\title{
Portais da tradução: limiares benjaminianos em Paul Celan e Yoko Tawada
}

\author{
Marianna llgenfritz Daudt ${ }^{1}$ \\ Monique Cunha de Araújo² \\ Gerson Neumann ${ }^{3}$
}

Programa de Pós-graduação em Letras, Universidade Federal do Rio Grande do Sul, Porto Alegre, RS, Brasil

Resumo: Nos ensaios Das Tor des Übersetzers oder Paul Celan liest japanisch (1996) [O portal do tradutor ou Paul Celan lê japonês] e Rabbi Löw und 27 Punkte (2007) [rabino Löw e 27 pontos], a escritora e tradutora Yoko Tawada, oriunda de um contexto exofônico JapãoAlemanha, excursiona pelas poesias de Paul Celan. No primeiro, ela analisa a tradução japonesa e constata a pervivência e a traduzibilidade propostas por Walter Benjamin na célebre reflexão da Tarefa do Tradutor. Em Rabbi Löw und 27 Punkte, Tawada investiga a misticidade da poética celaniana imbricada com o conceito de História. Por último, no ensaio $\mathrm{Ma}$ und $\mathrm{Mu}$ (2007) [Ma e Mu] ela verifica a história fragmentada japonesa, entremeada de limiares. O objetivo deste artigo é analisar a tradução e a crítica tradutória de Tawada, sobretudo a partir de suas leituras de Celan, sob um olhar nos conceitos benjaminianos de alegoria, parábola e história.

Palavras-chave: Benjamin; Tradução; Tawada; Celan.

Title: Translation portals: Benjamin's thresholds in Paul Celan in the light of Yoko Tawada

Abstract: In the essays Das Tor des Übersetzers oder Paul Celan liest japanisch (1996) [The Gate of the Translator, or Celan Reads Japanese"] and Rabbi Löw und 27 Punkte (2007) [Rabbi Löw and 27 points], the writer and translator Yoko Tawada, from an exophonic Japan-Germany context, analyzes the poetics of Paul Celan. In the first, she analyzes the Japanese translation and notes the "continued existence" and translatability proposed by Walter Benjamin in the celebrated reflection of the Translator's Task. In Rabbi Löw und 27 Punkte, Tawada investigates the mystique of celanian poetics imbricated to the concept of History. Finally, in the essay Ma und $\mathrm{Mu}$ (2007) [Ma and Mu] she checks the fragmented Japanese history, interspersed with thresholds. The purpose of this article is to analyze Tawada's

\footnotetext{
${ }^{1}$ Doutoranda do Programa de Pós-graduação em Letras da Universidade Federal do Rio Grande do Sul (UFRGS) em Estudos de Literatura (Teoria, Crítica e Comparatismo Literário). Bolsista CAPES. Orcid: http://orcid.org/0000-0001-9485-2316

E-mail: maridaudt@gmail.com

${ }^{2}$ Doutoranda na linha de pesquisa em Teoria, Crítica e Comparatismo do Instituto de Letras da UFRGS. Mestre em Literaturas de língua alemã pela mesma universidade com Bolsa da CNPq. Orcid: http://orcid.org/0000-0003-0759-3614

E-mail: mcunhadearaujo@gmail.com

${ }^{3}$ Professor Associado de Literatura e Língua Alemã na UFRGS. Doutorado em Ciências da Literatura pela Freie Universität Berlin - FU-Berlin (2004) com bolsa DAAD. Orcid: http://orcid.org/0000-0001$\underline{5809-6998}$
}

E-mail: gerson.neumann@gmail.com 
translation and critical translation, especially from his Celan readings, in the light of Benjamin's concepts of allegory, parable and history.

Keywords: Benjamin; Translation; Tawada; Celan.

\section{Apresentação}

Poesia: é qualquer coisa que pode significar uma mudança na respiração. Quem sabe se a poesia não faz o caminho - também o caminho da arte com vista a uma tal mudança? Talvez ela consiga, já que o estranho, ou seja, o abismo e a cabeça de Medusa, o abismo e os automátos, parecem ir numa e na mesma direcção - talvez ela consiga então aí distinguir entre estranheza e estranheza, talvez a cabeça de Medusa se atrofie precisamente aí, talvez aí fracassem os automátos - neste breve e único momento (CELAN, 1996, p. 54).

$A$ vida de um poema pode ser assimilada de uma vida anterior passageira em que 0 momento-presente se fixa e se projeta em um futuro, dignificando uma vivência eterna. $A$ pervivência, ou a continuidade da vida, evocada pela poesia de Paul Celan e da qual emana sua traduzibilidade, é única. A associação da simbologia judaica cabalística no interior de sua poética transmite ao historiador uma pausa, um flash, no momento passado. Essa poesiaevento, da qual a tradução emerge de um ponto singular e dele derivam outros pontos, como um irradiar efusivo de um esplendor, legitima sua vida posterior, algo que se caracteriza neste artigo pela imagem do passar por um portal. Para o tradutor de Celan, a tarefa consiste não em decodificar o passado, mas captá-lo em sua essência, em suas bases, carregar suas ruínas e transformá-las em presente.

Para avistar o momento-presente a partir dos vestígios de ruínas do passado cujo rastro a ideia do progresso apagou, é necessária a exegese mística da obra poética, que se transveste, sobretudo, por meio de alegorias e parábolas. Os acessos ao puro e ao mórbido localizam-se na mesma passagem, um tênue portal em um ponto místico da obra celaniana, onde a tradução tem a função de chave motora: revelar a história pelo recolhimento dos fragmentos esquecidos, abandonados; das partes corrompidas pela barbárie ou em prol do progresso. A análise da tradução japonesa e da construção da poesia de Paul Celan realizada pela tradutora e escritora Yoko Tawada evocam, principalmente, a ideia de passagem mística, em que tradução se interliga à história em um determinado momento. Nesse momento, certamente, os fantoches articuladores de um passado linear fracassam e a cabeça de medusa se atrofia, dando lugar a uma estranheza necessária na libertação da linguagem.

Dentro desses pressupostos, este artigo busca analisar, a partir de três ensaios de Yoko Tawada, como a tradução e a história se manifestam e são responsáveis pela reprodução de eventos que não possuem, necessariamente, um status factual, mas ganham relevância nas histórias culturais devido à atribuição de uma historicidade mística ao longo de seu percurso 
temporal e cultural. Para tal análise, serão utilizadas algumas das teorias de tradução e de história benjaminianas - nas quais, por vezes, Tawada também se alicerça -, em que se observa como a historicidade pode ser utilizada como um recurso alegórico capaz de complementar ou mesmo de tornar possível uma tradução e suas releituras de fatos míticos. Como apoio teórico recorre-se também ao conceito de alegoria e às discussões sobre o traduzir de alegorias de Henri Meschonnic, devido à consonância que se estabelece entre suas formulações e as de Benjamin abordadas e à pertinência de suas definições no âmbito deste estudo. As parábolas e as alegorias são perpassadas pelos conceitos de história e tradução, e trazem à tona a magia e a misticidade em que tais conceitos sempre se viram envolvidos. A representação dos portais evidenciada neste artigo tem o objetivo de notabilizar o momento único da criação da obra poética, de abrir as amarras da barbárie e de escolhas impositivas, configuradas no passado, e de servir de passagem, à la Alice, para um mundo íntimo interior, místico, da gênese da produção poética.

\section{A traduzibilidade inerente ao original: 0 audível não-dito}

A traduzibilidade é uma propriedade essencial de certas obras - o que não quer dizer que a tradução seja essencial para elas, mas que uma determinada significação contida nos originais se exprime em sua traduzibilidade ${ }^{4}$ (BENJAMIN, 2013, p. 104).

Com o trecho acima, Yoko Tawada encerra seu ensaio Das Tor des Übersetzers oder Celan liest Japanisch [O portal do tradutor ou Celan lê japonês] publicado na coletânea Talisman [Talismã], publicado em 1996. No ensaio, Tawada efetua uma espécie de decodificação da tradução japonesa do livro de poesia de Paul Celan Von Schwelle zu Schwelle [De limiar a limiar ${ }^{5}$ ]. $O$ texto do ensaio, como comenta Tawada, emerge a partir de uma leitura de Gershom Scholem. Tawada traz, nesses escritos, alguns dos aspectos principais de suas estratégias narrativas, como a conceituação do que vem a ser tradução e sua compreensão da alteridade fundamental da linguagem. Algumas de tais percepções advêm de seu permanente processo de escrita bilíngue, situação em que um tradutor se sente mais livre para ver formas de traduzir fora de uma ideia de literalidade ou de sentido limitado, transformando e reformulando a língua nos textos (MATSUNAGA, 2002).

$\mathrm{Na}$ língua japonesa, a associação de símbolos - enquanto unidades linguísticas - indica o sentido da palavra japonesa, caracterizada por sua composição ideográfica. Dessa forma, os símbolos constituem-se de um vínculo gráfico do qual resulta o significado. Isto revela, então, que os símbolos com significados distintos são unidos entre si para uma nova significação. No

\footnotetext{
${ }^{4}$ Neste artigo, foram utilizadas as traduções de Susana Kampff Lages de Walter Benjamin para o português.

${ }^{5}$ Para a tradução dos títulos de algumas poesias de Paul Celan foi utilizada a tradução de Cláudia Cavalcanti publicada em 2017.
} 
referido ensaio, Tawada dialoga com algumas das proposições benjaminianas presentes em $a$ Tarefa do Tradutor, publicado por Walter Benjamin na Alemanha pela primeira vez em 1923. A figura alegórica do portal [Das Tor] evidencia a lógica da traduzibilidade, evidente na poesia de Paul Celan.

A pergunta primordial sobre a traduzibilidade de um texto, sobretudo de um texto poético, efetua no ensaio de Tawada forte relação com a conceituação da obra traduzida e seu ideal literário enquanto produto poético. A preocupação de Tawada reside no entendimento tradicional da tradução cujo resultado implica em uma reprodução perfeita de seu original em contraponto com a concepção de que a própria tradução aloca em si a sua originalidade: "Com a questão da 'traduzibilidade', não quero dizer se um poema encontra uma imagem [Abbild] perfeita em uma língua estrangeira, mas se sua tradução também pode ser literatura"6 (TAWADA, 1996, p. 121-122). Evidentemente, Tawada argumenta em prol de um ponto de vista iluminado, sobretudo, na célebre reflexão de Benjamin sobre a traduzibilidade. Ela explica posteriormente que a tradução não é uma cópia, é um processo que dá novo corpo aos significados do original, com sons, signos e pensamentos diferentes. De maneira semelhante, para Benjamin, há um significado(s) específico(s) inerente(s) ao original que se manifesta em sua traduzibilidade, uma transformação e uma renovação capazes não apenas de expandir a vida de um texto, mas de lhe renovar em um "mais tardio e vasto desdobramento"(BENJAMIN, 2008, p.69).

Em a Tarefa do Tradutor, Benjamin discute a relação da linguagem com o ato de traduzir, os meandros dos sentidos entre uma tradução e seu original. O filósofo propõe que a boa tradução não comunica, não enuncia, mas transmite algo que lhe é superior: "aquilo que se reconhece em geral com inapreensível, o misterioso, o "poético"? (BENJAMIN, 2013, p. 102). Quando Tawada investiga a tradução e a sua legitimidade como literatura, ela encontra a indagação estética de Benjamin sobre a tradução do que é "poético" em um texto literário, definido por ele como "aquilo que o tradutor só pode restituir ao tornar-se, ele mesmo, um poeta?" (BENJAMIN, 2013, p. 102) Entretanto, conforme aponta o autor, há de se ter cuidado com tal proposição, pois ela admite o juízo de que a tradução possui em si uma independência de seu original, que levaria à pressuposição de que a tradução existe em função de seu leitor. Mas, antes disso, ela é como hóspede em um sistema vivo, na qual sua existência depende da criatura-original: "É lícito chamá-la [a conexão entre a tradução e o original] de natural ou, mais precisamente, de conexão de vida. Como as manifestações de vida estão intimamente ligadas ao ser vivo, sem significarem nada para ele, assim a tradução precede do original" (BENJAMIN, 2013, p. 104).

Nessa ligação de vida, no ensaio O portal da tradução ou Celan lê japonês, Tawada comenta que "muitas pessoas afirmam que a boa literatura é intraduzível" (TAWADA, 1996, p. 121). Por isso, quando ainda não sabia ler em alemão, pensava que, para poder ter acesso à literatura alemã propriamente, seria necessário aprender a língua e lê-la no original; então

\footnotetext{
${ }^{6}$ Os trechos de Yoko Tawada, originados da língua alemã, foram traduzidos pelos autores deste artigo.
} 
seu problema para poder ler a "boa" literatura estaria encerrado. Entretanto, ao se deparar com a tradução japonesa da coletânea de Celan, Von Schwelle zu Schwelle, fascinou-se: "Eu me perguntava na ocasião se as poesias dele poderiam não ter qualidade, pois eram traduzíveis" (TAWADA, 1996, p. 122). A questão levantada por Tawada se refere à legitimidade da literatura em tradução e sobre a escolha de termos para uma suposta equivalência, questões antigas na teoria tradutória. Tawada examina o encaixe das formas japonesas realizadas no poema celaniano pelo tradutor Mitsuo liyoshi e conclui que ele se insere em um contexto particular conceitual "de que deve haver um abismo entre as línguas, no qual todas as palavras mergulham". Isto significa compreender que há um espaço intermediário de comunicação e transformação entre as línguas, um espaço onde os significados se misturam e se revelam livres para criação e recriação:

\footnotetext{
Depois que eu aprendi a ler literatura alemã no original, descobri que minhas impressões não eram uma ilusão. Deve haver um abismo [Kluft] entre as línguas no qual todas as palavras mergulham. Cada vez mais me ocupava com a questão do porquê as poesias de Celan poderem alcançar um mundo estrangeiro ao da língua alemã (TAWADA, 1996, p. 126).
}

Para ela, sobretudo na tradução de Liyoshi, existe a forte impressão de que o original foi idealizado por Celan já com um olhar na língua japonesa ("ins Japanische hineinblicken" p.125). A ideia de que as línguas se relacionam entre si, evidentes para ela na análise entre o original e a tradução, evoca, entre outras ideias, a noção benjaminiana da afinidade entre as línguas. Segundo Tawada, na constituição da tradução japonesa das poesias da coletânea Von Schwelle zu Schwelle, na corporeidade do radical Tor 門 [portal; portão] se pode observar o poder do alcance do mundo estrangeiro das poesias de Celan (TAWADA, 1996, p. 127). A descoberta do uso do radical para a formação dos ideogramas sino-japoneses esclarece, para Tawada, a chave de sentido de toda a coletânea e, muito além disso, expressa a corporização da "traduzibilidade" da literatura de Celan (TAWADA, 1996), pois "todos os signos que são compostos pelo radical Tor têm, em um plano semântico, algo a ver com portal" [Tor] (p. 123).

$\mathrm{Na}$ análise da tradução japonesa da coletânea, Tawada constata sete ideogramas contendo o radical para portal 門. No título da coleção, não é difícil de compreender a presença do radical 門, pois entende-se a sentença Schwelle 閾 como entrada, limite inicial, da qual a palavra portal interliga-se completamente, ou seja, um limiar no qual "não existe uma fronteira específica para atravessar, mas migrar de uma fronteira a outra" (TAWADA, 1996, p.124). Na tradução do poema Von Schwelle zu Schwelle para o espanhol por José Luis Reina Palazón, admitiu-se esta ideia de portal, também presente na palavra Schwelle, traduzido para De umbral en umbral. No poema Ich hörte sagen [Ouvi dizer], o radical localizase na composição na palavra ouvir 聞, ideia presente em toda poética de Celan: portas, portais e entradas associam-se ao verbo ouvir, como no recorrente uso da palavra hebraica Shibboleth, cuja nomeação (que provém da parte de uma planta que contém grãos), nada tem a ver com o significado real com que foi usada. Na verdade, esse dizer marcava os efraimitas 
para a entrada na morte, e o ouvir os identificava nessa jornada. No valor semântico do termo "ouvir" há, tanto em português quanto em alemão - conforme sugerido por Celan - a coexistência da imagem de umbral; limiar, como na formação da palavra Hörschwelle [Limiar auditivo], a intensidade mínima de som que o ouvido humano é capaz de captar.

No título do terceiro poema da coletânea, Leuchten [luzir], vê-se um portal e uma pessoa embaixo dele para significar o termo luzir: 閃. A justificativa de Tawada para a união de um portal e uma pessoa para a significação do termo advém da ideia de que o termo Leuchten, na realização fonética, admite a palavra "ich" [eu] no meio. O pronome não aparece no poema, mas os equivalentes pressupostos, como "mir" [mim] e du" [você] e "uns" [nós], cujos ideários remetem, no poema, à salvação quebrantada por uma irradiação efusiva, que adentra.

A presença do radical 門 segue na construção dos versos do poema Mit Äxten spielen [jogar com machados], o qual a palavra Stunden [horas] é resultado da união dos símbolos para "tempo" e "entrelugar", em que entrelugar [Zwischenraum] é representado pela combinação de "sol" e "portal": 間. Nesse poema, Tawada lembra a frase de Scholem em Autoridade religiosa e mística ${ }^{7}$, na qual prega que

quanto mais precisa é uma exegese mística, maiores são as chances de reconhecimento contínuo de um texto quando transformado pela tradução, mesmo em seu sentido literal. Torna-se um portal através do qual passa a mística, um portal que sempre se mantém aberto (SCHOLEM apud TAWADA, 1996, p. 130).

Indubitavelmente, a figura do portal, sobretudo na cabala judaica, assume forte significação nos poemas de Celan. A Mezuzá (do hebraico, "umbral"), por exemplo, afixada a sete palmos do chão no umbral de portas e portais faz lembrar aos judeus seu criador, e a passagem por esses portais (selados com um beijo no mezuzá) evoca à rememoração das orações. As colunas e portas têm a função de separar dois espaços, expressam a ideia de ascensão, unindo céu e a terra, divino e mundano. Também na Bíblia, no livro de João, há diversas passagens sobre portas, a mais significativa neste caso é a auto intitulação de Jesus como meio de chegar a Deus: "Eu sou a porta; qualquer pessoa que entrar por mim, será salvo. Entrará e sairá; e encontrará pastagem" (BÍBLIA, João, 10, 9). 0 insistente portal ressurgido dos poemas na forma de radical na formação ideográfica sino-japonesa consiste não somente como um meio de constatação da traduzibilidade benjaminiana e a revelação da intimidade das línguas, mas antes disso, configura uma união entre vida e morte, em que a passagem se abre em diferentes significações.

\footnotetext{
7 Prólogo do livro Zur Kabbala und ihrer Symbolik publicado no Brasil sob o título A cabala e seu simbolismo (1978) na série Debates da Editora Perspectiva.
} 
O encontro da alegoria do portal, presente na traduzibilidade de Von Schwelle zu Schwelle, converge com as ideias expostas em Ethics and politics of translating (2007), de Henri Meschonnic, afluindo ao paradigma de Benjamin. Meschonnic comenta o papel da alegoria no processo de tradução: um processo que caminha junto de sua difusão e tem o poder de o modificar ou moldar (de acordo com a intenção dos tradutores) ao transmutar seu sentido, seu conteúdo, sua forma de ser lida, entre diversos outros aspectos de sua recepção. Para o autor, traduzir é um ato que mostra a interação entre linguagem, poema ${ }^{8}$, ética e política (MESCHONNIC, 2007, p.101), sem esquecer que esses elementos são amalgamados pelo conceito de história em que se encontram. Sobretudo em Celan, pode-se notar a suspensão do momento histórico a que se atrela, a "poesia-evento" de um presente que se cristaliza no passado e se projeta no futuro, por meio dos não-ditos, através da traduzibilidade que perdura, pervive. A análise de Meschonnic da tradução se relaciona fundamentalmente com a questão linguística, ou à força da contínua batalha entre o poema, compreendido como texto rítmico, e o signo, na estreiteza de sua natureza dual. Ele revela o problema em se pensar a linguagem nos termos do dualismo grego, de uma semiótica, pois isso é algo que na tradução do texto hebraico gera uma incongruência filológica, relativa ao domínio do signo: ideia que condiz a recusa de Benjamin à matriz grega da filosofia e seu forte vínculo ao pensamento judaico, sobretudo nas proposições de sua juventude. Meschonnic destaca a importância do ritmo na tradição do texto hebraico e, consequentemente, de como esse fator deve ser observado na sua tradução, pois o ritmo da Bíblia é radicalmente irredutível às categorias conceituais gregas de linguagem, de referência ocidental. Dessa forma, a tradução é o processo por meio do qual o paradigma teológico se torna a batalha por uma cadeia de deteologização da linguagem, do poema, da ética e do político contra o teológico-político, como aponta a pervivência da imagem portal na tradução japonesa.

Relativo a esta alegoria do portal, Tawada vê a tradução não de uma forma sacralizada, mas como abertura para novas acepções, como uma forma de acesso a novos conteúdos. Por este motivo, a ideia de ver a poesia de modo fechado é inadmissível, principalmente para os poemas de Celan, que não são, segundo ela, como propriedades cerradas. Na exegese mística dos poemas, sobretudo a partir da permanência e insistência do significado de abertura e limiaridade que a alegoria do portal evoca na tradução japonesa, Tawada é impelida a ver os poemas de Celan de outra forma: "Eu passei a ver os poemas de Celan como portais e não como casas, nas quais o significado seria mantido como uma propriedade. (...) As palavras de Celan não são recipientes, mas aberturas. Eu atravesso a abertura do portal cada vez que as leio" (TAWADA, 1996, p. 134).

\footnotetext{
${ }^{8}$ Compreendido como body-in-language, um continuum que se vale do ritmo como organização do movimento da fala e que implica a subjetivação de um sistema de discurso. (MESCHONNIC, 2007, p. 141) Além disso, o autor entende o poema como ato ético e político pelo qual os sujeitos são transformados, pois, do contrário, tratar-se-ia de poesia e não de poema (MESCHONNIC, 2007, p. 160).
} 


\section{Misticidade, parábola e as liminaridades imagéticas da linguagem}

A conexão mística presente nos versos de Paul Celan encontra espaço também em Yoko Tawada. Em Benjamin, há a linguagem pura como rememoração de Deus, ou de quando a palavra não era proibida, na pureza do Paraíso (BENJAMIN, 2013, p. 66), e isso remete à conexão de vida (e de morte) com a qual a poesia se constrói. Tal conexão lembra o impedimento da fala no meio do caos mórbido e a tarefa de redenção dos mortos (SELIGMANN-SILVA, 2017), ponto chave da escrita celaniana. Na crítica de Tawada, a questão da vida se conecta a uma forma de alegoria na linguagem que, revestida de recursos imagéticos (ideogramas e pontuações), traduz um mundo fragmentado e de significações múltiplas.

No ensaio de Tawada, Rabbi Löw und 27 Punkte [rabino Löw e 27 pontos], publicado na coletânea Sprachpolizei und Spielpolyglotte [Polícia da língua e poliglota jogador] em 2007, a análise da construção linguística e poética da poesia de Paul Celan entrecruza-se ao uso da parábola e da misticidade na tradução do silêncio, ou do impedimento do dizer. Tawada sugere, neste ensaio, a existência de elementos que não se abrem no processo de tradução, mas que se movem "com o corpo fechado" (TAWADA, 2007, p.39) do original para a tradução: como os sinais de pontuação. Eles são como entidades capazes de atravessar o portal da tradução sem se modificar para qualquer língua. A estranheza da colocação desses pontos efetua-se como um double bind, em que a linguagem surge e volta para ela mesma e dissolve a fala em silêncio. Esse mecanismo relaciona-se na poética à "necessidade e impossibilidade da construção do passado, à sua construção après coup na forma de ruínas" (SELIGMANNSILVA, 2007, p.41). Nesse sentido, a releitura histórica da questão dos pontos pode ser observada em uma conexão com a tradução que Tawada faz do poema de Celan sobre a lenda judaica da criação do Golem.

Na lenda, o rabino Judá Löw cria o Golem a partir do barro, uma criatura para lhe servir. Para Ihe dar vida, Löw escreve na testa dele a palavra hebraica emet ("verdade") e, para Ihe retirar a vida, bastava apenas apagar a primeira letra, revelando a palavra meth, ou "morto", retirando-lhe o nome vivificante de Deus. Tawada assume também neste ensaio a influência do filósofo e historiador Gershom Scholem, amigo de W. Benjamin, na sua poética. As letras correspondem aos elementos constitutivos do original, são as pedras a partir do qual se dá a criação. Para Scholem, citado por Tawada, a construção do Golem, o nome de Deus e as letras representam, especialmente, os registros de toda a criação. Além disso, na análise da poética de Celan por Tawada, o papel da figura de Golem fundamenta-se na ordem não do religioso, mas do divino, pois se trata da passagem da vida em seu sentido de criação, do "criar a vida" em todas as criaturas; contém ainda a definição do sagrado, que seria a fusão do humano com o cósmico. Essa fusão é o que permitiria ao humano dispor de um acesso mágico transcendental ao limiar cósmico, por isso o rabino [Rabbi] representa o sagrado e recria a vida; porém esta é uma imitação, cuja validade, porém, é interditada pela religião em seu 
movimento de tentar recriar homem, pois este não tem o direito a usar a palavra divina ou de instituir uma nova vida por meio da mesma magia geradora de Deus - a palavra, a gênesis. 0 religioso seria uma apropriação do papel da socialização e da ritualização do divino.

O poema Aquele, que diante da porta estava ${ }^{9}$, de Celan, abordado por Tawada é uma versão da lenda de Golem, porém com a adaptações e marcações que remetem à situação da Guerra vivida por Celan, dentre as quais, a autora nota a presença de duas linhas inteiras compostas apenas de pontos:

A este

Atirai também a porta da noite, Rabbi

Rasgai a porta da manhã, Ra- -

(TAWADA, 2007, p.42)

No início do ensaio, Tawada explica que foi aconselhada por Klaus Rüdiger Wöhrmann na leitura e análise desse poema: “'Celan' significa 'conte'!” (TAWADA, 2007, p. 39). No poema, a autora conta, literalmente, os pontos e faz uma série de experimentos com os sinais de pontuação, em busca do não dito. Ela nota que a primeira linha contém treze pontos e a segunda, quatorze, bem como a falta das letras " $b$ ", "b" e "i", de "Rabbi", de rabino, no último verso. Sua conclusão é a seguinte: "Eu traduzi os 13 pontos para a letra "B", os 14 pontos para um "B" e um "I" e devolvi-os à palavra "Rabbi" para que a palavra ficasse completa" (TAWADA, 2007, p. 43). A chave de significação do recurso imagético da pontuação se dá na medida daquilo que não se pode falar, que fica no entrelugar da linguagem: o não dito que diz. Nesse sentido, a "palavra mágica" para a decodificação dos versos reside no conselho de Wöhrmann:

Nessa brincadeira de letras, fica claro que também o "Rabbi" consiste em uma combinação de letras. E essas letras podem ser lidas simultaneamente como letras e como números. Como eu não pude partir os pontos, que se pareciam com duras nozes, contei-os. "Conta!": A palavra mágica para leitores de Celan (TAWADA, 2007, p.43)

Nesse limiar da linguagem, entre o não-dito presente imageticamente, a coisa/fragmento e o "conteúdo da verdade", a obra se configura não como "acidente

\footnotetext{
${ }^{9}$ Tradução de Elcio Loureiro Cornelsen. CORNELSEN, Elcio Loureiro. Os caminhos do Golem pela literatura. In: Os fazedores de Golems. NAZARIO, Luiz; NASCIMENTO, Lyslei (Orgs). Belo Horizonte: Estudos Literários da FALE/UFMG, 2004.
} 
histórico, mas substância de um passado para iluminação de um presente" (BARRENTO ${ }^{10}$, 2013, p.121). Na poesia de Celan, também a parábola - neste caso, a do Golem - se revela como característica da trans-historicidade, que se reporta à sua origem e se adapta historicamente de seus primórdios talmúdicos ao momento vivido pelo poeta na Segunda Guerra, uma tradução pautada na experiência do momento-presente. A poesia traz em si, ainda, além da contemplação mística das letras e sua codificação do não-dito, remontando à tradução judaica do Livro da Criação, a possibilidade de os pontos se converterem em letras na sua contagem, revelando a transcendentalidade existente nos signos e suas representações, como um portal pelo qual passa a mensagem em suas possibilidades de tradução histórica e semântica. Benjamin vale-se da parábola como forma de elucidar um discurso dentro de um universo estético que dialoga com seu tempo social e apresenta uma estratégia retórica funcional, dentro de um contexto histórico. A linguagem assume, nesse contexto, uma forma capaz de representar a historicidade no caráter imagético e linguístico, trazendo uma mensagem que, deslocando-se no tempo e nos diferentes contextos, revestese de uma faculdade mística em sua tradução e transtemporalização.

Em consonância com as considerações benjaminianas, Henri Meschonnic (2007; 2010) afirma que a parábola se revela em sua condição de continuum entre narrativa e temporalidade como algo não definível dentro das noções de temporalidade estruturalista, realizada no domínio de uma construção narrativa regida pelo domínio do signo, portanto de pretensão estável e dual entre significado e significante. A parábola, compreendida enquanto (evento) particular com um valor universal ou com o valor de um universal (MESCHONNIC, 2007, p. 71), está presente em grandes histórias e textos fundadores de valor transcendental e transcultural da humanidade, como exemplarmente na narrativa bíblica. A análise de Meschonnic sobre a Bíblia se aplica a diversos textos análogos em valor, ou seja, que estabelecem uma poética do continuum, um tipo de entidade que vai muito além do seu caso particular e que se vincula ao domínio do signo. Trata-se de uma parábola porque, sendo o tempo todo um exemplo particular, este exemplo vale para todos os idiomas, todos os textos e todos os tempos; e de uma profecia, porque é, depois de ter rejeitado as representações comuns da linguagem, o postulado de um impensado, contra todas as tradições, contra qualquer postulado teológico-político, uma verdadeira "revolução cultural" (MESCHONNIC, 2007, p. 120).

\section{Ilhas da história e construção do futuro}

No ensaio Ma e Mu (2007), Tawada associa memórias suas às reflexões em torno de ideias mítico-religiosas pertencentes às culturas do Japão e do Ocidente e discorre sobre os

\footnotetext{
${ }^{10}$ Do livro Limiares sobre Walter Benjamin (2013), ensaios e comentários de João Barrento sobre a tradução e pesquisa de Benjamin.
} 
possíveis impactos nessas sociedades, assim como em sua vida. Neste ensaio, ela elenca algumas histórias tradicionais religiosas e as examina principalmente em âmbito espacial e temporal. Tawada assume a impossibilidade de assimilação do modo de pensar tradicional, de como referido em livros de história. Ela ainda se aproxima de uma postura crítica quando comenta movimentos sociais e históricos do Japão e o comportamento deste país com relação à forma como controla questões de língua e religião, como no comentário sobre o espelho:

\begin{abstract}
Antigamente no Japão, o espelho não era considerado um objeto para reconhecer a si mesmo, mas uma passagem para o mundo dos mortos. Se uma mulher se olhasse no espelho, veria a sua mãe morta: um motivo antigo, que frequentemente aparece na literatura japonesa da Idade Média. Contudo, o mundo atrás do espelho não era entendido como o passado, ou seja, como um tempo já passado e perdido, mas como um outro lugar coexistindo com o presente. Às vezes, eu vejo o paraíso como a mãe morta no espelho imaginada pela filha, a utopia. Quando alguém me pergunta sobre a utopia, me sinto um pouco desconfortável. Não quero viver num espaço apertado entre o paraíso e a utopia. Para mim, não há nem um início, o paraíso, nem um fim, a utopia (TAWADA, 2007, p. 111).
\end{abstract}

A crítica ao "mundo atrás do espelho" se assemelha as proposições benjaminianas em suas Teses sobre o conceito de História (1985), em que a figura do autômato jogador de xadrez representa uma crítica ao materialismo histórico, crítica essa que ao longo do ensaio vai se desenvolver em torno do historicismo do qual se serve o materialista histórico, que se fundamentaria em uma visão eterna do passado, como se este fosse imóvel e pudesse organizar a "massa dos fatos"(BENJAMIN, 1985, p.231), dentro de uma marcha, de uma linha fixável de acontecimentos no tempo. Além disso, a construção de um tempo linear, em que o sujeito tem o objetivo utópico de compreender a vida em um constante avanço em busca de uma temporalidade no futuro, faz com que se percebam os nexos causais da história, mas "apenas como quem desfia "as contas de um rosário", ou seja, sem entender a fundamental relação entre os acontecimentos, ou a configuração do contato entre as eras. (BENJAMIN, 1985, p. 232).

Essa tentativa de imobilização do passado tomaria uma feição de evento messiânico, como se uma época pudesse ser retirada do curso homogêneo da história para tornar-se "uma oportunidade revolucionária de lutar por um passado oprimido". Benjamin entende a História como "objeto de uma construção cujo lugar não é o tempo homogêneo e vazio, mas um tempo saturado de 'agoras'" (BENJAMIN, 1985, p. 229). No momento em que o historicismo busca estabelecer um nexo causal entre os eventos históricos e extrair uma época determinada do curso da história, ele estaria reconhecendo o sinal de uma imobilização messiânica dos acontecimentos. Para Benjamin, o historiador consciente evitaria simplesmente contar ordenadamente os acontecimentos, mas captar a ideia de que as épocas entram em contato umas com as outras e, com isso, estabelecem um conceito de presente 
"como um agora no qual se infiltraram estilhaços do messiânico" (BENJAMIN, 1985, p.232). Esse processo de quebra de uma teleologia da história é remetido ainda à ideia dos antigos judeus de que o tempo, não sendo nem vazio nem homogêneo, pode ser um portal - como o espelho representado na cultura japonesa -, em que cada segundo seria uma possibilidade de passagem para o Messias em seu retorno.

Na visão de Tawada, o tempo é uma dimensão existencial que não pode apresentar tal duplicidade, pois está ligado à existência humana. Essa faceta transcendente não existe para um indivíduo moderno, que entende sua existência como linha temporal dotada de início e fim, nascimento e morte. Mircea Eliade observa que o homem religioso apresenta uma constante necessidade simbólica de retornar periodicamente a tempos passados em um esforço para restabelecer uma situação mítica de origem, daquilo que era in principium e explica que essa situação "pode parecer insuportável e humilhante aos olhos do homem moderno. Uma tal nostalgia conduz fatalmente à continua repetição de um número limitado de gestos e comportamentos" (ELIADE, 2010, p 82). Eliade prossegue com a proposição de que "De certo ponto de vista, (...) o homem religioso - sobretudo o das sociedades primitivas - é, por excelência um homem paralisado pelo mito do eterno retorno" (ELIADE, 2010, p 82)

Quando Tawada escreve que para ela não há nem "um início, o paraíso, nem um fim, a utopia" pauta-se na realidade de sua experiência, sem mistérios transcendentais paralelos. Ela rejeita a obrigação para com um passado mítico no presente através da figura da mãe morta ou da vida alicerçada na esperança de uma descrição imaginativa ideal. Há um desconforto com essa forma antiga ou tradicional de percepção da realidade e, por isso, busca em sua existência um caminho com reflexos do passado que não sejam ritualmente determinantes em sua conduta, apesar de aceitar sua construção pessoal a partir deles. Ao explicar que o espelho não era propriamente uma representação do passado, ela faz lembrar que as dimensões espaciais e temporais tendiam a se cruzar em uma espécie de limiar [Schwelle] que permitia a conexão das esferas do sagrado (ou mítico-religioso) e do profano. Limiares, recorrentemente, são representados para lembrar a possibilidade de integração e acesso entre os dois mundos, formando uma unidade cósmica que se confundia com a própria percepção da coisa real, pois a ideia do real despido de sua dimensão transcendente é uma construção recente.

A partir da menção à figura do espelho na tradição japonesa, Tawada passa a revisar de forma crítica a história do Japão com relação ao modo de conduzir sua formação cultural e ideológica:

Ao longo da história, o Japão, em vez de construir uma utopia, sempre tomou algum outro país como exemplo, tentando imitar o país escolhido e ultrapassá-lo. $O$ imitador não é muito criativo e, de modo algum, original. É como a segunda infusão de um chá. Mas a segunda infusão tem uma vantagem que agrada especialmente aos políticos covardes e irresponsáveis: pode-se observar se aquele que bebe da primeira infusão primeiro se 
queima. (...) Na Modernidade, os exemplos do Japão foram a França, a Inglaterra, a Prússia e os Estados Unidos. O hábito de tomar o exemplo de países realmente existentes em vez de desenvolver uma utopia não mudou. Isso quer dizer que o futuro nunca foi uma questão de distância temporal, mas geográfica (TAWADA, 2007, p. 112-113).

No trecho, Tawada denuncia o hábito japonês de importar costumes e impô-los à sociedade sem que eles façam parte de um movimento histórico-cultural natural. A ironia com que trata o desenvolvimento forçado daquilo que chama de "utopia" é retomada quando explica que a unificação da língua japonesa durante a Era Meiji no século XIX foi um processo forçado e também tomado de exemplo de outros países, em função de uma necessidade de unificação para que pudesse competir com os países do ocidente. $O$ governo japonês teria imposto um padrão linguístico (também histórico e cultural) que não correspondia aos muitos dialetos falados pelas diferentes classes sociais e em diferentes regiões no Japão. Ainda o mesmo padrão crítico será aplicado ao tratamento da história da religião japonesa:

A coleção de mitos "Kojiki" do século VIII tenta explicar a criação do mundo. Embora essa coleção contenha fragmentos interessantes da mitologia, não é possível ignorar que foi publicada para justificar o poder do imperador. Histórias baseadas no matriarcado, por exemplo, foram excluídas, reinterpretadas ou rescritas. No "Kojiki" é possível observar a trabalhosa tentativa de se adicionar o início ausente à História.-(TAWADA, 2007, p. 113)

Com essas críticas a autora denuncia como os elementos culturais podem ser utilizados como instrumentos de imposição e acabam por exercer influência em toda a constituição histórica de coletivos e seus membros. No que se refere à essa injunção, Benjamin afirma que "nunca houve um monumento da cultura que não fosse também um monumento da barbárie. É, assim como a cultura não é isenta de barbárie, não o é, tampouco, o processo de transmissão de cultura" (BENJAMIN, 1985, p.232). Nesse processo de transmissão forçada sem a restituição dos fragmentos da história, baseou-se a história tradicional japonesa. 0 apagamento de histórias baseadas no matriarcado pode ter sido algo de dimensões consideráveis, pois o modo de produção agrícola como já o utilizado pelas tribos japonesas há alguns séculos tende a valorizar a fecundidade da terra e sacralizar a figura da mulher, vista como importante pilar em tais sociedades. O objetivo do Kojiki, por outro lado, é estabelecer e legitimar a família imperial japonesa por meio de sua inclusão na representação mitológica da criação do mundo.

Após fazer uma breve análise e comparar as genealogias sagradas do Kojiki e da Bíblia ocidental, Tawada redireciona a atenção do leitor e o conteúdo do texto do mito japonês de criação do mundo realizada pelos deuses Izanagi e Izanami para sua própria forma de ver e entender a história do mundo: 
Izanami e Izanagi remexeram na terra lamacenta com uma foice. Pingos caíram de sua ponta sempre no mesmo lugar, e aí formaram uma ilha firme na qual os dois, ao final puderam enfim ter relações tranquilamente. A ilha era o pré-requisito para a reprodução. Também eles eram, ao mesmo tempo, os produtos dela, pois Izanami deu à luz muitas ilhas antes de dar à luz deuses. Como o tempo pode ser representado apenas espacialmente, seria possível comparar as épocas japonesas a ilhas. As ilhas não estão ordenadas linearmente, mas espalhadas pelo oceano, que não tem fim nem começo. Elas são imóveis, ainda assim flutuam sobre a imensidão da água, permanecendo, contudo, sempre recolhidas em si mesmas (TAWADA, 2007, p. 114 e 115).

A imagem das ilhas japonesas como épocas históricas remete à ideia da quebra da teleologia da História como parte do raciocínio contemporâneo, ou seja, o fim da concepção na qual a história é compreendida como movimento progressivo, ou como uma linha do tempo que se inicia e segue rumo a estados superiores em desenvolvimento constante. Contra essa visão linear e quantitativa, Benjamin opõe uma percepção qualitativa da temporalidade, fundada, de um lado, na rememoração, de outro na ruptura messiânica/revolucionária da continuidade, reforçada pela impressão a seguir:

Quando eu estudava no Japão, muitas vezes tive a sensação de que as diferentes épocas históricas eram tratadas como ilhas no mar. Especialmente a concepção confucionista da história chinesa, que ainda possui caráter de modelo no Japão, parecia-me um oceano cheio de ilhas: existiu a dinastia $A$, a dinastia $\mathrm{B}$, a dinastia $\mathrm{C}$ e muitas outras dinastias. É certo que elas existiram numa ordem cronológica, mas eu logo a esqueci, pois não conseguia entender por que motivo a dinastia $B$ seguiu a dinastia $A$ e não o contrário. Cada dinastia teve seu apogeu, suas crises e seu fim, mas nunca pude constatar desenvolvimento que perpassasse todas elas (TAWADA, 2007, p. 115).

Em seguida, a autora escreve que, de tempos em tempos, uma nova ilha cai do céu, ou talvez da foice de Izanagi e Izanami. Ela explica que as ilhas já existentes permanecem inalteradas e que há espaço para todas. Na história do Japão, quando o budismo foi introduzido, não se deixou de seguir também o xintoísmo, já estabelecido. Ou, quando as ciências europeias passaram a nortear o modo de pensar no mundo, as cerimônias japonesas também não foram abandonadas. Ela pondera, porém, que vive em um tempo no qual se considera o processo de ocidentalização generalizado no mundo um fator de perda da cultura do oriente, mas ela mesma se diz incapaz de afirmar se um dia houve uma cultura concreta a ser perdida. Seus questionamentos a levam à conclusão de que ela não precisa de uma tradição rígida que seja exclusivamente própria, pois prefere apenas explorar outras culturas e encontrar nelas algo que a inspire. 
O título "Ma e Mu" traz uma formulação bastante trabalhada pela autora, que é o estar em um espaço de entremeio, ou um não-espaço. Sua posição de outsider pode ser observada por exemplo, quando afirma que apenas pode escrever fora da língua materna, pois mesmo quando utiliza o japonês, não deixa de se valer do mesmo estranhamento de quem não pertence a essa língua, como se fosse possível descolar-se de sua cultura e viver em um espaço intermediário que se criaria entre as línguas, ou entre culturas. Mais uma vez, ela mistura componentes linguísticos a religiosos, e propõe que se deveria confrontar a lógica de que apenas é possível pertencer a uma única religião (como, por exemplo, ser ou budista ou cristão) ou a uma única ideologia e buscar compreender o espaço da vida ou a compreender si mesmo como um entremeio, um espaço entre espaços e tempos. No trecho a seguir ela explica as sílabas "Ma" e "Mu":

\begin{abstract}
Alguns filologistas afirmam que a sílaba "ma" aparece, na maioria das línguas, na palavra que significa "mãe" e isso se daria devido à natureza dos seres humanos. Em japonês, "ma" não significa "mãe", mas "entremeio". "Mama" também não significa "mamãe", mas "deixar como está". "Mu" significa "nada", "mi" "fruta" ou "corpo", "me" "olhos". O tempo, que não se pode medir nem preencher, é uma "ma". "Ma" também pode significar "magia" ou "um espírito perigoso". E justamente esse momento, fora de qualquer ordem temporal, pode ser o tempo mais interessante para a poesia (TAWADA, 2007, p. 119 e 120).
\end{abstract}

Neste trecho, a ideia de preenchimento evoca a história tradicional como algo vazio e homogêneo, necessário de ocupação. O entrelugar temporal, em que a poesia se mostra mais relevante, como evoca Celan na epígrafe deste artigo, o momento breve em que a fissura temporal se abre alocando a mística do instante, em que a história admite uma pureza. Em Benjamin, assim como a história, a língua também tem seu estado puro, em que cada parte de seu todo constitui um fragmento que se conecta com uma espécie de integralidade mágica. A tradução é como a tentativa de compreender um momento-presente, deve-se ter em mente a busca para transmitir legivelmente uma totalidade ao aqui e ao agora. Esse processo, entretanto, se visto como algo fixo ou estável - como querem os defensores da literalidade bem como do historicismo ou do materialismo histórico - tende a se perder em um erro de dogmatismo. O papel do historiador, nesse caso, possui um viés revolucionário, impedindo a tempestade (o progresso) de apagar as ruínas coletadas pelo anjo da história, como aponta Michael Löwy a partir da interpretação das Teses sobre a história:

A revolução é o "correspondente" (no sentido baudelairiano da palavra) profano da interrupção messiânica da história, da parada messiânica do devir" (Tese XVII): as classes revolucionárias, escreve na Tese XV, estão conscientes, no momento da ação, de "romper o contínuo da história". A interrupção revolucionária é, portanto, a resposta de Benjamin às ameaças que faz pesar sobre a espécie humana a perseguição da tempestade maléfica chamada "Progresso" (...) (LÖWY, 2002, p. 205). 
Nesse sentido, dada a impossibilidade ou inadequação de se ter o tempo histórico como algo linear e ordenado, a tarefa do historiador consiste em colocar as imagens históricas dentro um determinado tempo, sob a pena de não serem legíveis e, desta forma, o historiador tem de traduzir os fatos passados por meio da síntese e/ ou da atualização. Esta função aproxima-se da tarefa do tradutor que também tem de encontrar um local e um momento de traduzibilidade dos textos. Daí sobreviria a sua proximidade com o original. Ambos buscam uma essência significativa cuja finalidade seria deixar transparecer a essência de um original (texto ou fragmento histórico; ruína) e mantê-lo vivo ao longo dos tempos, apegam-se a uma tarefa-renúncia.

\section{Considerações finais}

A recorrência da figura do portal nos versos da coletânea Von Schwelle zu Schwelle de Paul Celan na tradução japonesa corrobora a teoria benjaminiana de que a traduzibilidade se manifesta também no original e de que as línguas possuem entre si uma relação íntima. Contudo, essa relação não se refere ao ideário tradicional da crítica da tradução de uma semelhança entre as línguas, mas relaciona-se a conexão de vida entre o original e sua tradução. O original ganha a capacidade de continuar a vida, perviver, por meio da tradução, através dos desdobramentos de seus sentidos, portanto não se trata de uma perda ou de alguma imitação inferior, como querem alguns teóricos de tradução.

Alegoricamente, a figura do portal atinge seu ápice quando, na interpretação de Yoko Tawada, ressignifica a poesia e se abre em significações codificadas. A repetição do radical sino japonês para portal na maioria das traduções japonesas da coletânea configura na tradução, de fato, um elemento mágico pelo qual se arrolam não só sentidos múltiplos, mas o momento-presente. $O$ instante captado das ruínas da história se escancara no portal místico, e faz com que a tarefa do tradutor e do historiador se assemelhem: a do recolhimento dos não-ditos da poesia e dos vestígios de passados não contados. O estranho entrelugar que habita a significação poética e os momentos fragmentados da história retratam, na acepção benjaminiana, o local que tradutores e historiadores devem ocupar.

A supressão da história das matriarcas das tribos na invenção do mito japonês da criação do mundo atesta que a barbárie não está fora da cultura, na verdade, faz parte da construção dela. A leitura crítica feita por Yoko Tawada dos versos celanianos, no que tange à misticidade da pontuação, sugere uma linguagem muito além das letras, em que tudo fala, tudo significa. Nesse processo de revelação dos fragmentos de verdade, as matriarcas japonesas também significam para história, pois a História, como mostra Tawada, é como ilhas em que momentos históricos alocam-se em diferentes espaços, negando assim uma linearidade historicista, da mesma forma que Benjamin critica em suas teses. 
Yoko Tawada esforça-se em demonstrar que a tradução é uma constante nas línguas e nas histórias dos diferentes países e contextos linguísticos. A autora resiste às noções puristas e de viés nacionalista de que exista uma língua ou cultura pura ou original, inclusive quando utiliza o exemplo de seu país de origem, como quando critica a entrada do Japão na modernidade como a "Prússia do Oriente", junto com a institucionalização da língua japonesa definida nacionalmente na educação, além da importação do conhecimento e comportamento ocidentais por parte do governo japonês da Era Meiji. Os instrumentos de imposição acabam por exercer influência em toda a constituição histórica dos coletivos e seus membros, como bem observou Benjamin ao dizer que os monumentos de cultura são também monumentos de barbárie (1985). Essa barbárie foi bem conhecida por Celan, que a invoca e representa nos silêncios de sua poesia. Celan e Tawada são escritores que vivem entre línguas, literal e figurativamente; seus textos e personagens vivem cruzando limiares. Assim, traduzir é uma preocupação central para ambos os escritores, que não escondem sua interlocução com Benjamin. Os tradutores também são criadores, seus textos encerram toda a magia e os perigos que contém a força das palavras: a tradução parece, enganosamente, ser um exercício transparente de mover o significado de um conjunto de palavras para outro; porém como Benjamin já observa em muitos de seus ensaios, a tradução é um ato é repleto de perigos e significados em camadas.

\section{Referências}

BARRENTO, João. Limiares sobre Walter Benjamin. Florianópolis: Ed. da UFSC, 2013.

BENJAMIN, Walter. A tarefa-renúncia do tradutor. Trad. Susana Kampff Lages. In: BRANCO, Lucia Castello (Org). A tarefa do tradutor, de Walter Benjamin: quatro traduções para o português. Belo Horizonte: Fale/UFMG, 2008, p. 66-81.

BENJAMIN, Walter. A tarefa do tradutor. In: Escritos sobre mito e linguagem. Trad. Susana Kampff Lages e Ernani Chaves .2a Ed. São Paulo: Editora 34, 2013.

BENJAMIN, Walter. Obras escolhidas I. Magia e Técnica, arte e política. Ensaios sobre literatura e história da cultura. Trad. Sérgio Rouanet. São Paulo: Brasiliense, 1985.

BENJAMIN, Walter. Origem do drama trágico alemão. Trad. João Barrento. Lisboa: Assirio \& Alvim, 2004.

BENJAMIN, W. Origem do drama barroco alemão. Trad. Sérgio Paulo Rouanet. São Paulo: Brasiliense, 1984.

BENJAMIN, Walter. Passagens. Belo Horizonte: Editora UFMG; São Paulo: Imprensa Oficial de São Paulo, 2009.

BÍBLIA, N. T. João. In: BÍBLIA. Português. Sagrada Bíblia Católica: Antigo e Novo Testamentos. Tradução de José Simão. São Paulo: Sociedade Bíblica de Aparecida, 2008.

CELAN, Paul. "O meridiano". In: Arte Poética. Edição e Tradução de João Barrento. Lisboa: Cotovia, 1996. 
CELAN, Paul. Cristal Trad. Claudia Cavalcanti. São Paulo: Iluminuras, 2017.

ELIADE, Mircea. O sagrado e o profano: a essência das religiões. Trad. Rogério Fernandes. São Paulo: Editora WMF Martins Fontes, 2010.

LÖWY, Michael. Walter Benjamin: aviso de incêndio uma leitura das teses "Sobre o conceito de história". São Paulo: Boitempo, 2005.

LÖWY, Michael. A filosofia da história de Walter Benjamin. Estudos Avançados, São Paulo, v. 16 (45), p. 199- 206, 2002. https://doi.org/10.1590/S0103-40142002000200013

MATSUNAGA, Miho. Schreiben als Übersetzung. Die Dimension der Übersetzung in den Werken von Yoko Tawada. In: Zeitschrift für Germanistik, vol.12, no.3, 2002, pp. 532-546. Disponível em <www.jstor.org/stable/23976357>. Acesso em 16 de fevereiro de 2019.

MESCHONNIC, Henri. Ethics and politics of translating. Tradução e edição de Pier-Pascale Boulanger. Tel Aviv: Benjamins Translation Library, 2007.

MESCHONNIC, Henri. Poética do traduzir. Trad. Jerusa Pires Ferreira e Suely Fenerich. São Paulo: Perspectiva, 2010.

SELIGMANN-SILVA, Márcio. Double Bind: Walter Benjamin, a tradução como modelo de criação absoluta e como crítica, in Leituras de Walter Benjamin, org. Márcio Seligmann-Silva, São Paulo: FAPESP: Annablume, 2007.

TAWADA, Yoko. Bogo no soto e deru tabi. Tóquio: Iwanami, 2003. Título em japonês: エクソ フォニーーー母語の外へ出る旅.

TAWADA, Yoko. Das Tor des Übersetzers oder Celan liest Japanisch. In: Talisman. Tübigen: Konkursbuch, 1996, p. 125-138.

TAWADA, Yoko. Die Krone aus Gras. In. Sprachpolizei und Spielpolyglotte. Tübingen: Claudia Gehrke, 2007, p. 63-84.

TAWADA, Yoko. Kleist auf Japanisch. In. Sprachpolizei und Spielpolyglotte. Tübingen: Claudia Gehrke, 2007, p. 85-90.

TAWADA, Yoko. Ma und Mu. In. Sprachpolizei und Spielpolyglotte. Tübingen: Claudia Gehrke, 2007, p. 110-121.

TAWADA, Yoko. Rabbi Löw e 27 pontos. In. Sprachpolizei und Spielpolyglotte. Tübingen: Claudia Gehrke, 2007, p. 38-44.

TAWADA, Yoko. Verwandlungen. Tübingen: Ed. Claudia Gehrke, 1998.

Recebido em: 21/05/2019

Aceito em: 02/07/2019 